\title{
A formação da identidade docente na licenciatura em química e suas relações com a aprendizagem significativa a partir da análise do Modelo de Ensino de Gowin
}

\section{The formation of teaching identity in chemistry degree and its relation with significative learning as from the analysis of the Gowin Model}

${ }^{1}$ Débora Lázara Rosa deboralazararosa@gmail.com

1 Ana Néry Furlan Mendes

1 Andrea Brandão Locatelli

\section{RESUMO}

Neste trabalho os processos da aprendizagem significativa serão analisados a partir da interação entre formação inicial de professores de Química e materiais educativos através do instrumento heurístico V de Gowin. Foram referenciados autores como David Ausubel e Marco Antônio Moreira que fundamentam as bases conceituais e metodológicas desse trabalho na compreensão e análise da estruturação dos saberes docentes. A prática pedagógica experimentada no ambiente escolar se constitui valiosa por proporcionar saberes práticos, trocas de informações com profissionais mais experientes, vivência da rotina e dos desafios da sala de aula que promovem saídas pedagógicas diversas diante da imprevisibilidade do cotidiano pedagógico, proporcionando possíveis reflexão das ações realizadas que venham contribuir de forma significativa nos processos de ensino e aprendizagem. Dessa forma ações como estágios supervisionados e participação dos licenciandos em programas como o Programa Institucional de Bolsa de Iniciação à Docência - PIBID, contribuem significativamente na formação da identidade docente, e, no caso aqui tratado, o curso de licenciatura em Química em que a didática e as ações desenvolvidas em sala de aula têm promovido a aprendizagem e o envolvimento dos bolsistas do PIBID/CEUNES/QUÍMICA motivando-os na produção dos saberes pertinentes à profissão.

Palavras chave: Formação inicial de professores. Ensino de química. Aprendizagem significativa.

\section{ABSTRACT}

In this work, the processes of meaningful learning will be analysed from the interaction between initial training of teachers of Chemistry and educational materials through the Gowin heuristic instrument V. We have referred authors such as David Ausubel and Marco Antônio Moreira who base the conceptual and methodological bases of this work on the understanding and analysis of the structuring of teaching knowledge. The pedagogical practice experienced in the school environment is valuable because it provides practical knowledge, exchanges of information with more experienced professionals, experience of the routine and the challenges of the classroom that promote different pedagogical outputs in the face of the unpredictability of the pedagogical routine, providing possible reflection of the actions which contribute significantly to the teaching and learning processes. Thus, actions such as supervised internships and the participation of graduates in programs such in the Institutional Program of the Initiation to Teaching Scholarship - PIBID, contribute significantly to the formation of the teaching identity, and, in this case, the undergraduate course in Chemistry in which didactics and the actions developed in the classroom have promoted the learning and the involvement of PIBID/CEUNES/CHEMISTRY fellows motivating them in the production of knowledge relevant to the profession.

Keywords: Teaching education. Chemistry education. Meaningful learning.

1 Centro Universitário Norte do Espírito Santo CEUNES/UFES. 


\section{INTRODUÇÃO}

Ensinar é uma atividade complexa que envolve saberes pedagógicos aliados às práticas e vivências pessoais de quem o faz. Estar apto a ensinar exige também que alguém esteja predisposto a aprender e, nesse sentido, torna-se pertinente promover processos educativos que dinamizem o conhecimento, especialmente levando em consideração aqueles experienciados pelos sujeitos envolvidos.

Segundo Roldão (2005) o ensino se configura como “o ato de fazer aprender alguma coisa a alguém” a partir de currículos preestabelecidos ou necessidades específicas de aprendizagem, tendo em vista a elaboração de resposta a um problema ou o preenchimento de uma lacuna que torne o conhecimento relevante.

No Brasil os cursos de formação de professores para atuarem na educação básica são de competência de Instituições de nível superior, segundo a Lei de Diretrizes e Bases da Educação Nacional nº 9394/96. A formação docente deve se basear no sujeito como parte de um todo, ou seja, sujeito dos processos educativos que contemplam suas experiências de vida, mas também no fazer pedagógico em exercício da profissão, como citado por Nóvoa (2009):

“...o trabalho do professor consiste na construção de práticas docentes que conduzam os alunos à aprendizagem [...]. Ser professor é compreender os sentidos da instituição escolar, integrar-se numa profissão, aprender com os colegas mais experientes. É na escola e no diálogo com os outros professores que se aprende a profissão. O registro das práticas, a reflexão sobre o trabalho e o exercício da avaliação são elementos centrais para o aperfeiçoamento e a inovação.”

Dessa forma se faz necessário desenvolver uma formação que contemple além dos saberes referentes à área de conhecimento a ser ensinada e os pedagógicos, também os saberes experienciais para o exercício de uma prática transformadora, em que os conhecimentos exclusivamente curriculares não são suficientes para o exercício da prática docente, pois os professores a todo instante constroem e reconstroem seus saberes a partir da prática que exerce em sala de aula (TARDIF; LESSARD, 2005). Com isso, torna-se pertinente a formação pedagógica para atuação docente em que o exercício profissional seja ação fértil de produção de saberes permanentemente.

O processo de formação inicial de professores perpassa por questões de ordem política, social e econômica no Brasil sendo necessário discussões, reflexões e ações no âmbito escolar. Neste sentido, Freire (1996) afirma que "órgãos competentes deveriam priorizar o empenho de formação permanente dos quadros do magistério" possibilitando uma formação adequada às exigências de nossa sociedade.

\section{A CONSTITUIÇÃO DA IDENTIDADE DOCENTE DURANTE A FORMAÇÃO INICIAL DE PROFESSORES}

A formação inicial de professores se configura etapa importante na constituição profissional pois, nesse momento, tem-se a possibilidade de desacomodar e produzir saberes docentes que fundamentarão a prática pedagógica. Nesse sentido, Tardif (2014) afirma que “o saber dos professores parece estar assentado em transações constantes entre o que ele são (incluindo as emoções, a cognição, as expectativas, a história pessoal dele, etc.) e o que fazem. ”

Chamamos atenção também no processo de formação inicial para a falta de vínculo entre teoria e prática aplicada que, segundo Esteban e Zaccur (2002), apontam como lacuna na formação inicial de professores: 
“A cisão criada entre teoria e prática, entre pensar e fazer, que leva a falsa impressão de que a docência se caracteriza pela aplicação imediata de metodologias formuladas em alguma instância "superior" à sala de aula, fazendo da sala de aula o lócus da ação, como se o agir desobrigasse o pensar."

A prática educativa na formação de professores se configura instrumento de reflexão acerca da necessidade de promover ações e atitudes que contribuam de forma efetiva no processo formativo da identidade docente. Segundo Schön (1992) teoria e prática se constituem em dados indissociáveis, porém a organização dos processos formativos docente dificulta a interação entre ambos, visto que estes dois fatores têm ocupado diferentes espaços na formação de professores. A falta de vínculo entre teoria e prática estabelece relações superficiais entre ensino e aprendizagem efetivando a posição de professores transmissores e alunos receptores de conhecimento, posição esta que contribui com a falta de motivação de ambos frente aos desafios dos saberes realmente significativos.

Para Maldaner e colaboradores (2007) os saberes advindos da vivência permitem estabelecer relações entre conhecimento prévio e conceitos científicos, com vistas a promoção de novas aprendizagens. Assim, nos processos pedagógicos que movimentam os saberes advindos da prática pedagógica, aliados às determinações conceituais e metodológicas das disciplinas ditas de "linha dura", ou seja, as disciplinas das áreas de conhecimentos específicos, promovem aos alunos em processo inicial de formação oportunidades de experienciar as correlações entre a teorização das disciplinas específicas e as relações que estas poderiam estabelecer com a ciência dos saberes cotidianos.

As reflexões em torno de questões que envolvem os processos de ensino e aprendizado apontam como entraves a falta de: contextualização, interdisciplinaridade, processos interativos de construção de saberes, promoção de questionamentos para o desenvolvimento dos processos cognitivos relacionados à aprendizagem de alunos. Todavia é urgente que estas questões estejam inseridas e trabalhadas de maneira efetiva nos cursos de licenciaturas e formação de professores, dando a estes o suporte e as ferramentas básicas para construção de processos educativos mais significativos.

\section{A APRENDIZAGEM SIGNIFICATIVA REQUER PREDISPOSIÇÃO PARA APRENDER A ENSINAR}

Os processos de ensino e aprendizagem devem se estruturar a fim de que o estudante seja protagonista em sua aprendizagem, seja ele mesmo o responsável por aprender enquanto o professor se ocupe em criar possibilidades de aprendizagem construindo práticas docentes que conduzam os mesmos à produção de saberes significativos, que privilegie o pensar a partir da curiosidade pelas ações realizadas em sala de aula. Essa dinâmica se contrapõe ao que ainda é recorrente nas salas de aula da Educação Básica. Novak e Gowin (1996) refletem acerca desta questão: “[...] professores têm trabalhado duramente para conseguirem o que é ao mesmo tempo impraticável e cansativo e, portanto, oneroso. Temos esperado deles que causem aprendizagem em estudantes quando, obviamente, aprendizagem tem que ser causada pelo estudante. ”

De acordo com Moreira (2008) aprender significativamente requer interação entre conhecimentos prévios e o conhecimento potencialmente relevante já existente nos processos cognitivos do aluno. Sob esta perspectiva, Braathen (2012) define a aprendizagem significativa como "novo conceito que se agrega ao conhecimento já existente, ampliando-o e modificando-o tanto em termos qualitativos quanto em quantitativos". Assim, os processos de formação de professores precisam privilegiar a formação significativa entre os sujeitos envolvidos, ou seja, alunos futuros profissionais e os estudantes da escola básica, com vistas a fomentar o protagonismo de ações que dinamizem a produção de saberes outros e novos entre os mesmos. Ausubel, Novak e Hanesian (1980) propõe alguns parâmetros para condução de atividades que promovam a aprendizagem significativa, são eles: 
“1. Que o estudante manifeste uma predisposição (postura) para aprender significativamente, isto é, uma disposição de relacionar material novo de maneira substantiva (não literal), e não arbitrária, na sua estrutura cognitiva.

2. Que o material novo a ser aprendido seja potencialmente significativo para ele ou ela, ou seja, que possa ser relacionado à estrutura de conhecimentos do estudante numa base substantiva (não literal) e não arbitrária. ”

São recorrentes as conversas nas salas de professores sobre uma aula que foi bem elaborada e pensada, mas que não teve êxito com os alunos. De acordo com Moreira (2011), para que a aprendizagem seja potencialmente significativa o aluno deve ser capaz de agregar ao novo conhecimento apresentado os significados relacionados ao contexto do conteúdo ministrado, sendo necessário que haja o que o autor chama de "negociação" de significados, que requer a interação entre os sujeitos envolvidos no processo na efetivação da aprendizagem. Dessa forma percebe-se o quão desacreditado se torna o ensino propedêutico, em que se negligencia os questionamentos, os conhecimentos prévios em prol da transmissão de conhecimentos para o aluno, sendo este o responsável por reestruturar sua aprendizagem a partir da "negociação" dos conhecimentos que lhe são apresentados, identificando as possíveis relações entre o novo que lhe é apresentado e o que ele já possui de conhecimento.

\section{MATERIAIS EDUCATIVOS E SUAS RELAÇÕES COM O DIAGRAMA DE ENSINO DE GOWIN}

Dentre as várias possibilidades de relacionar o que se deseja promover de aprendizado e o que o estudante reconhece como fundamental para sua compreensão dos conteúdos, têm-se inúmeras metodologias de ensino que possam contribuir na condução de saberes significativos. Entende-se neste caso por metodologias de ensino, as formas de abordagens diferenciadas do conteúdo como utilização de materiais didáticos que possibilite a interação do educando com o objeto em estudo (atividades mediadoras), aulas diferenciadas que coloque o educando em uma posição ativa de construção do conhecimento para que junto com o educador o processo de ensino e aprendizagem se torne mais eficiente.

Essas formas de abordagens do conteúdo podem ser, conforme Machado (1999), um "instrumento privilegiado para a elaboração de uma forma de pensar em Química” e será utilizada em paralelo a abordagem de conteúdos que é realizada em sala de aula, favorecendo a apropriação de conteúdos significativos. Torna-se necessário por parte do educador proporcionar ao educando formas de interação no ensino que estimulem os questionamentos, a curiosidade pelo saber e o gostar de conhecimento. As metodologias de ensino têm todas essas potencialidades pela articulação entre instrumentos e signos.

O desenvolvimento dos processos cognitivos se alicerça nos contextos sociais de acordo com a perspectiva histórico cultural de Vygotsky (1988). Essa interação é essencial para o desenvolvimento de qualquer ser humano. Moreira e Massoni (2011) associa a ocorrência desse processo à mediação entre instrumentos e signos, que podem ser construídos social, histórica e culturalmente no meio em que se estabelece.

Associando essas perspectivas teórico metodológica à utilização de materiais educativos, têm-se os instrumentos, que seriam os materiais educativos propriamente ditos. Moreira e Massoni (2011) os definem como "algo que pode ser usado para fazer alguma coisa, e signo é algo que significa alguma coisa”. Assim os materiais educativos, por serem instrumentos de aprendizagem, promovem a interação social com objetivos pedagógicos potencialmente significativos.

A fim de compreender essa relação, o diagrama de ensino de Gowin traz a perspectiva de compartilhar significados a partir de conteúdos pré-estabelecidos, promovendo a interação entre aluno/professor/material edu- 
cativo. Essa relação permite que o material educativo seja um instrumento mediador permitindo que aluno e professor transformem a ação educativa por meio dos jogos em aprendizagem potencialmente significativa.

As experiências vivenciadas pelos licenciandos são decisivas nas escolhas das abordagens teórico metodológicas que estes usarão em suas aulas. A epistemologia desses saberes advindos da prática requer articulação destes conhecimentos com os saberes profissionais, dos livros e das experiências do professor. Isso implica na percepção de que a forma de ensinar pode ser mais significativa no processo de aprendizagem do que o conteúdo propriamente dito, visto que as práticas educativas determinam o nível de interesse que o aluno irá criar com o seu objeto de aprendizagem a partir do desenvolvimento da inteligência do aluno, produzindo a interação entre individual e coletivo em sala de aula.

A relação que se estabelece a partir dessa interação pode ser compreendida a partir do diagrama de ensino de Gowin:

Figura 1 - O modelo tríadico de Gowin

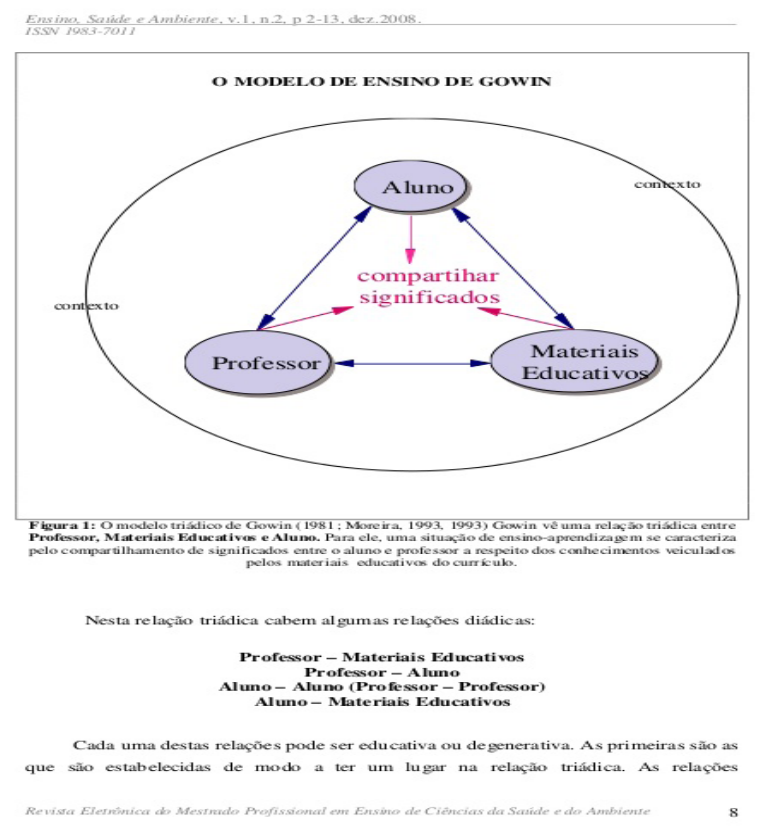

Fonte: (MOREIRA, 2008).

Esta interação promove o que Moreira (2008) classifica como negociação de significados, que é a compreensão que o aluno tem a respeito daquilo que o professor pretende ensinar a partir da utilização de materiais educativos. O processo interativo de construção do conhecimento se torna essencial nesse contexto de aprendizagem, no qual o material educativo se estabelece como instrumento mediador desse processo e as ações desenvolvidas entre aluno e professor se caracterizarão interacionistas pela dinâmica estabelecida neste contexto de aprendizagem. Este autor cita algumas considerações importantes para que a relação do modelo de Gowin se estabeleça: 
Figura 2- Processo de negociação de significados no contexto da aprendizagem significativa.

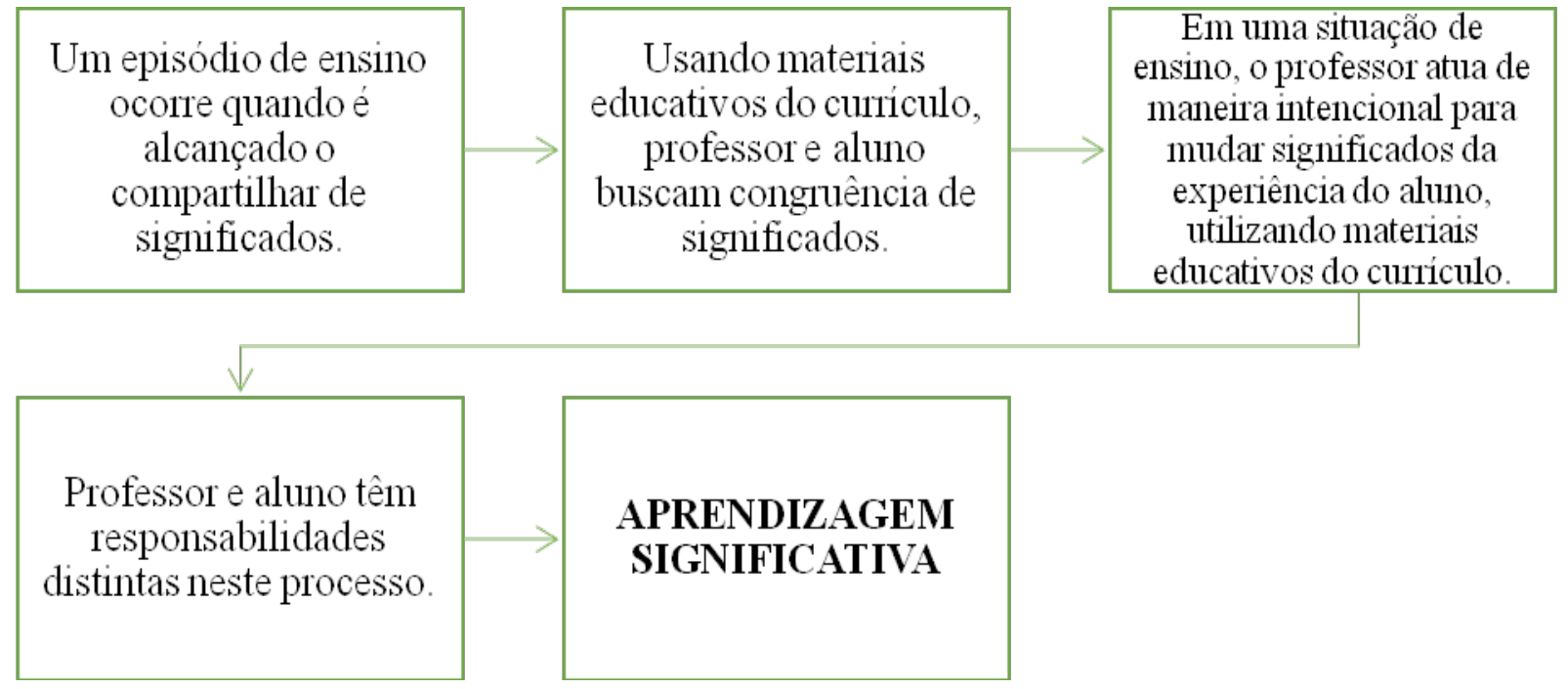

Fonte: (MOREIRA, 2011, p. 97-99)

Estas relações permitem analisar parte do processo da aprendizagem significativa a partir da interação que o professor estabelece entre aluno e material educativo. O que determina o sucesso do processo ensino e aprendizagem são as interações compartilhadas entre os sujeitos envolvidos e o significado que as ações efetuadas, através do material utilizado, promoverão de oportunidades para o desenvolvimento dos processos educativos. A construção do conhecimento a partir dos processos interativos passa pela motivação que o professor estabelece entre objeto de estudo/pesquisa e o significado que este acarretará ao conhecimento adquirido.

Assim questionamos o quanto as relações que se firmam nesse processo devem se alinhar aos objetivos de ensino que o professor desejar atingir. Para tanto leva-se em consideração os conhecimentos prévios dos estudantes por meio dos conceitos estruturantes chamados subsunçores ${ }^{2}$ que serão associados no alcance de outros objetivos de aprendizagem (Ausubel et al., 1980; Moreira, 1999a, 1999b)

Portanto, neste trabalho utilizaremos o diagrama V de Gowin como instrumento para estabelecer as relações existentes entre a estruturação da identidade docente dos bolsistas do Programa Institucional de Bolsa de Iniciação à Docência (PIBID) e a produção de materiais didáticos, durante as atividades desenvolvidas em uma escola de educação básica.

\section{OBJETIVOS}

Ao analisar o processo de formação inicial de professores de Química a partir da elaboração de métodos de ensino diversificados, por meio da Teoria da Aprendizagem Significativa, pretende-se fomentar as relações didáticas pedagógicas que venham contribuir na formação da identidade docente e promover interações de aprendizagem entre os bolsistas do PIBID e a produção de material educativo para o ensino de Química. Sob esta perspectiva objetivou-se:

2 Segundo Moreira (2011, p.28): "subsunçores podem ser proposições, modelos mentais, construtos pessoais, concepções, ideias, invariantes operatórios, representações sociais e conceitos já existentes na estrutura cognitiva de quem aprende." 
- Utilizar as orientações da Teoria da Aprendizagem Significativa em seu instrumento V de Gowin e em sua relação tríadica aluno, professor e material educativo para a constituição da identidade docente de Licenciandos em Química.

- Proporcionar ao aluno de Licenciatura em Química participantes do PIBID ferramentas educativas que o permitam conduzir o Ensino de Química de maneira significativa nesse programa de ensino em escolas de educação básica.

- Avaliar as contribuições desse processo educativo na estruturação dos saberes docentes por meio da análise e reflexão do diagrama V de ensino de Gowin.

\section{6}

\section{METODOLOGIA}

O percurso metodológico desenvolvido caracterizou-se conforme a definição de Bogdan e Biklen (1994), sendo a presente pesquisa considerada como qualitativa, que segundo os autores apresentam as seguintes características:

Figura 3 - Características da investigação qualitativa.
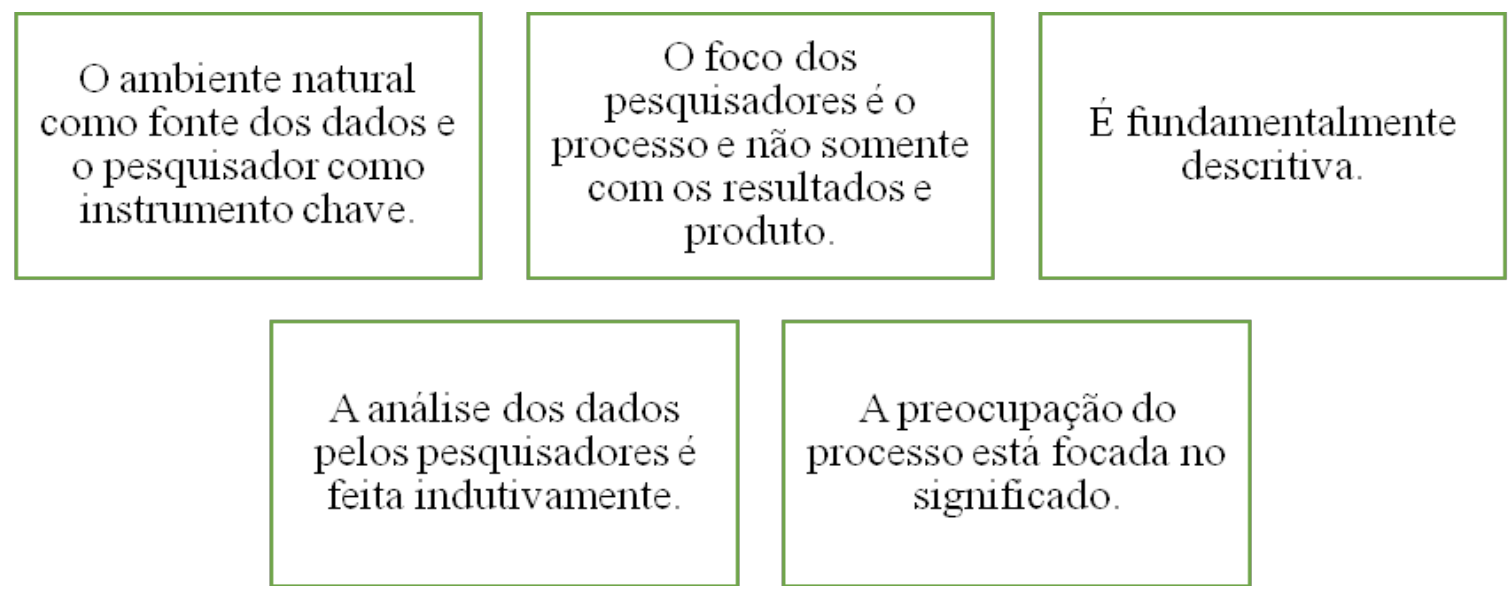

Fonte: (BOGDAN; BIKLEN, 1994, p. 47 - 51). Adaptação das autoras.

Tais apontamentos acerca da pesquisa qualitativa se desdobram, especificamente para este trabalho, na pesquisa ação ou pesquisa participante, que segundo Gil (2008, p.30) “é caracterizada pelo envolvimento dos pesquisadores e dos pesquisados no processo de pesquisa”.

Assim, foram propostos aos licenciando em Química da Universidade Federal do Espírito Santo, do Centro Universitário Norte do Espírito Santo (UFES/CEUNES) participantes do PIBID, a elaboração e produção de materiais educativos para o Ensino de Química a partir da escolha de conteúdos que foram trabalhados no ensino médio na escola a qual eles participam do programa. Essa escolha levou em consideração as necessidades de aprendizagem dos alunos da Educação Básica na referida escola, após levantamento prévio de quais assuntos poderiam ser trabalhados de maneira efetiva a fim de atribuir significados aos conteúdos que os alunos do ensino médio tiveram mais dificuldade ao longo do período letivo. Os assuntos previamente levantados pelos bolsistas foram: Propriedades periódicas e aperiódicas dos elementos químicos, Forças intermoleculares, Estequiometria, Identificação de Funções orgânicas, Isomeria Plana e Geométrica.

A produção do material foi orientada pela professora supervisora com o objetivo de apresentar aos bolsistas do PIBID/CEUNES/QUÍMICA formas de se trabalhar a interdisciplinaridade e os processos interativos de 
construção de saberes a partir de questionamentos realizados em sala de aula. A contextualização do ensino de Química também foi um pré-requisito para a elaboração do material educativo, que levou em consideração os conhecimentos prévios dos alunos do ensino médio. Nessa etapa do processo os bolsistas do PIBID/CEUNES/ QUÍMICA foram para as salas de aulas e a partir da interação com os alunos foram coletando dados que seriam utilizados posteriormente na confecção do material.

Após este levantamento os licenciandos se reuniram para definir o tipo de material educativo a ser produzido para cada conteúdo previamente estabelecido com a professora orientadora, bem como a melhor maneira de abordar os assuntos estabelecendo relações de interação entre aluno/professor/material educativo. Foi produzido também uma tabela periódica com grafia em Braille contendo os símbolos dos elementos químicos, a massa atômica e o número atômico que foram impressos na sala de recursos audiovisuais da escola, para atender as necessidades de aprendizagem de alunos com deficiência visual.

Após a montagem do cronograma de trabalho os licenciandos se reuniam para elaborar o plano de trabalho e as atribuições de cada um no projeto a ser desenvolvido. Participaram da elaboração e confecção dos materiais educativos 10 licenciandos em Química do PIBID/CEUNES/QUíMICA. As atividades que foram desenvolvidas durante todo o projeto duraram aproximadamente quatro meses, desde a coleta de dados em sala de aula com os alunos da Educação Básica, a elaboração do plano de trabalho, a confecção do material educativo e sua aplicação em sala de aula com os alunos da escola participante. Foi um trabalho intenso que requisitou a interação entre bolsistas, professor de Química da escola participante e alunos do Ensino Médio.

Para elaborar o material educativo os bolsistas utilizaram os Parâmetros Curriculares Nacionais (PCN’s, 1996) e o Currículo Básico Comum (CBC, 2008) das escolas estaduais do estado do Espírito Santo, como referência para se trabalhar as habilidades e competências propostas nos documentos orientadores.

A Figura 4 apresenta as fotos da preparação do material que foi aplicado na referida escola pelos monitores do PIBID:

Figura 4 - Materiais educativos elaborados pelos bolsistas do PIBID/CEUNES/QUÍMICA.
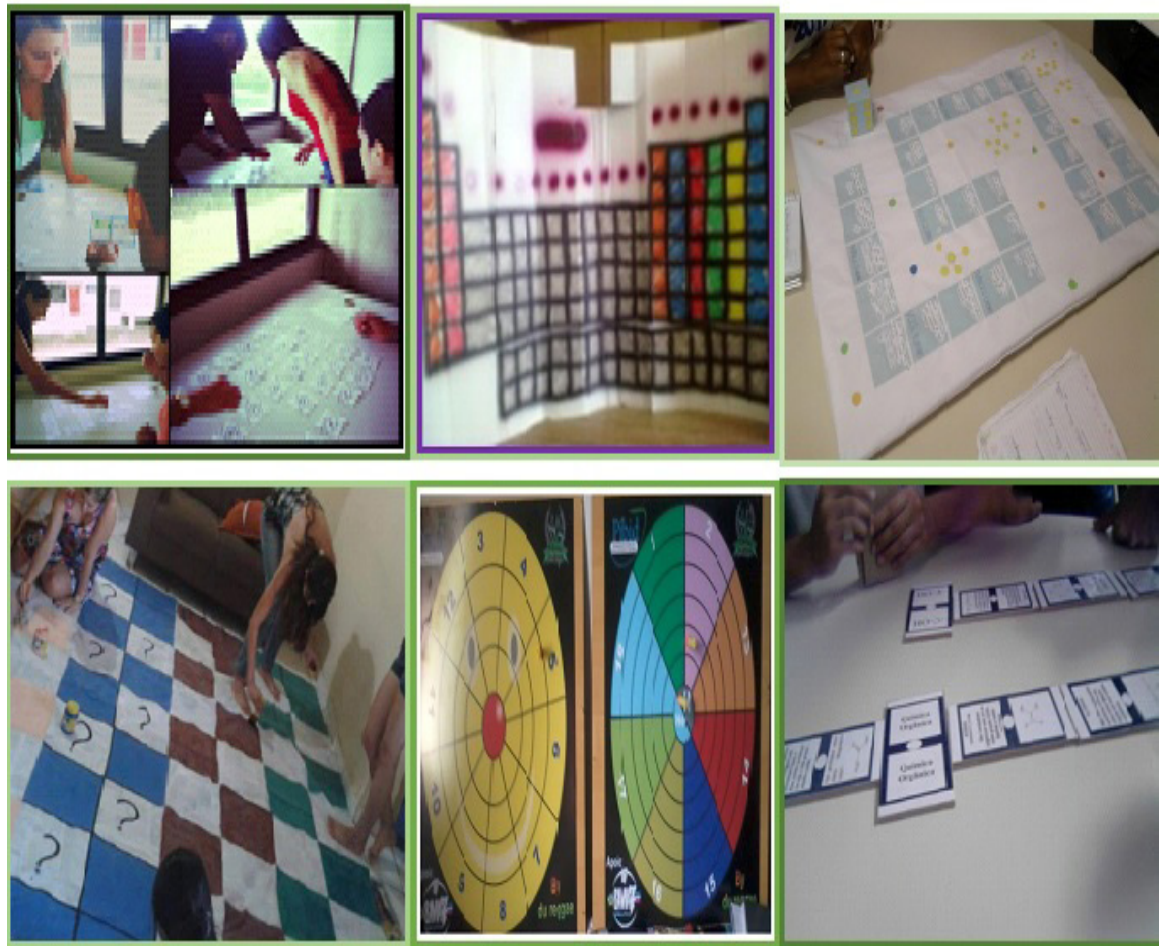

Fonte: Arquivo pessoal dos autores. 


\section{APRESENTAÇÃO E DISCUSSÃO DOS RESULTADOS}

O material educativo elaborado pôde ser utilizado nas três séries do ensino médio, abordando questões de Química que puderam ser trabalhadas a partir das necessidades de aprendizagens elencadas pelos próprios alunos da Educação Básica.

Esta proposta de atividade promoveu a interação dos bolsistas do PIBID/CEUNES/QUíMICA com metodologias de ensino que os colocaram em contanto com questões primordiais do processo de ensino e aprendizagem, como a associação dos conhecimentos específicos em Química a ações cotidianas, geração de questionamentos a partir das questões levantadas durante a aplicação do material educativo e a preparação da aula pelos bolsistas do PIBID/CEUNES/QUÍMICA. A realização destas atividades foi um momento de exercitar as competências docentes necessárias, oportunizando o trabalho interdisciplinar de maneira contextualizada.

As experiências advindas da prática docente se apresentam sob a perspectiva da formação em serviço, promovendo a reflexão orientada das ações e fundamentações metodológicas de ensino de um profissional com maior experiência. Nesse caso, o professor orientador tem importante colaboração nos processos formativos da identidade docente dos bolsistas do PIBID, através da interação estabelecidas entre escola de Educação Básica e Universidade. Tal colaboração advém dos anos de experiência no âmbito escolar, das leituras e pesquisas que nortearam as práxis pedagógicas do professor supervisor, das formações vivenciadas ao longo dos anos e das saídas pedagógicas que foram articuladas a cada novo desafio vivenciado em sala de aula. Porém, os bolsistas do PIBID chegam às escolas de educação básica com uma bagagem teórica de leituras, debates reflexivos, participações em congressos estruturas ao longo da formação inicial que junto ao professor supervisor podem proporcionar um trabalho colaborativo rico em trocas de saberes e potencialidades aos pares envolvidos.

A partir da análise dos resultados obtidos foi possível, através do diagrama V de Gowin, apresentar a interação entre domínios conceituais e domínios metodológicos, bem como as interações que se estabeleceram a partir da proposta de construção de material educativo pelos bolsistas do PIBID/CEUNES/QUíMICA, com o objetivo de aliar o pensar ao executar promovendo aprendizagem a partir das relações estabelecidas entre os sujeitos envolvidos no processo.

O diagrama apresenta um panorama do processo educativo que permite contemplar as possibilidades de aprendizagens, além da formação e reformulação de conceitos envolvidos nos episódios de aquisição de saberes que se estabeleceram a partir da atividade proposta. Esta análise pode ser melhor compreendida a partir do diagrama V da Figura 5. 
Figura 5 - O diagrama V de Gowin e as interações do processo de ensino e aprendizagem.

\section{FILOSOFIA:}

Os saberes experienciais influenciam os processos formativos da identidade docente.

\section{TEORIAS:}

Teoria da Aprendizagem Significativa de David Ausubel, Modelo de ensino de Gowin, A perspectiva Histórico Cultural de Vygotsky, Processos Formativos da Identidade Docente.

\section{Princípios:}

Aprendizagem Significativa na formação inicial de professores, desenvolvimento da identidade docente, Processos interativos aluno/professor a partir da mediação.

\section{CONCEITOS:}

$\begin{array}{lrr}\text { Conhecimento } & \text { prévio, } & \text { Criação de } \\ \text { Identidade } & \text { Docente, } & \text { Processos } \\ \text { Formativos, } & \text { Materiais } & \text { educativos, } \\ \text { Diagrama V. } & & \end{array}$

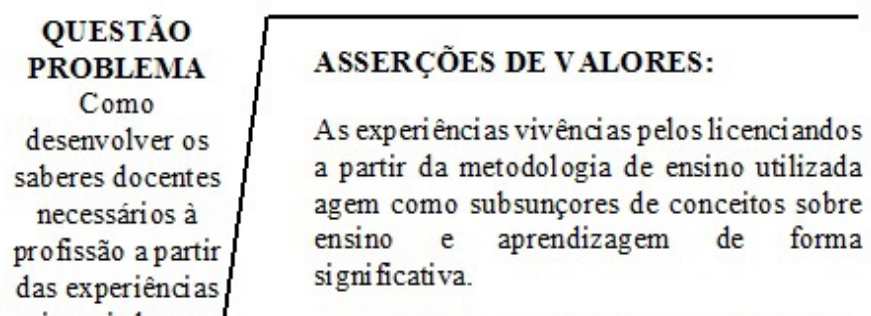

ASSERÇÕES DE VALORES:

As experiências vivências pelos licenciandos a partir da metodologia de ensino utilizada agem como subsunçores de conceitos sobre ensino e aprendizagem de forma significativa.

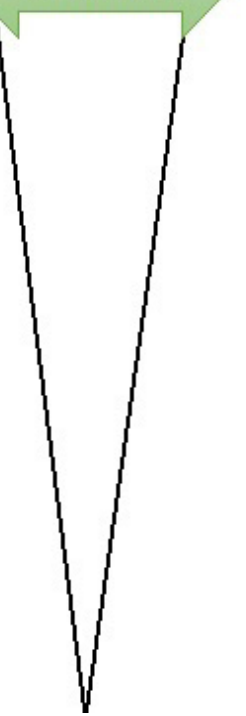

\section{ASSERÇÕES DE CONHECIMENTOS:}

Os métodos de ensino que requer do professor uma postura de transmissão de saberes perante seus alunos, não é capaz de proporcionar a estes mecanismos de aprendizagem.

\section{TRANSFORMAÇÕES:}

As atividades desenvolvidas dentro do ambiente escolar permitem aos licenciandos perceber as relações existentes entre teoria e prática, contribuindo para super ação da ideia que ao fim da graduação eles se encontram preparados para "ser professor."

\section{REGISTROS:}

As teorias de aprendizagem influenciam a prática educativa fornecendo subsidios para se estabelecer relações de ensino e aprendizagem potencialmente significativas.

Fonte: Sistematização dos autores.

O diagrama $\mathrm{V}$ de Gowin apresenta um cenário de como os saberes concebidos a partir da prática docente levam a formulação de novos conceitos, ou ainda, como os conhecimentos pré-existentes nas estruturas cognitivas dos licenciandos puderam ser aplicados de maneira a incorporar os saberes docentes ao seu campo de atuação profissional.

As metodologias de ensino oportunizam aos bolsistas do PIBID/CEUNES/QUíMICA estabelecer relações formativas entre os aspectos teóricos abordados durante sua formação e a prática pedagógica desenvolvida em seu futuro local de trabalho. Essa dinâmica de aprendizagem mobiliza saberes advindos da prática oferecendo ao licenciando saberes formativos que são reelaborados constantemente, fundamentando um reservatório de saberes necessários a atividade docente. Ao vivenciar o cotidiano escolar na produção e aplicação de materiais, os licenciandos se preparam para o agir pedagógico durante a formação inicial. Desta maneira, os bolsistas têm a oportunidade de vivenciar os desafios e potencialidades da sala de aula durante a formação inicial, estruturando em suas redes cognitivas saberes docentes que serão utilizados como eixos estruturantes ao longo da construção de sua identidade docente.

Assim, ao estabelecer correlações entre os saberes docentes que potencialmente movimentam aprendizagens significativas na formação inicial de professores e o desenvolvimento de ações didático pedagógicas no ambiente escolar, têm-se a possibilidade de afirmar métodos de ensino que fomentam o processo de formação de professores que vem sendo formados por um saber dinâmico. Saberes estes mobilizados nas atividades pelo saber da experiência que vai se construindo na prática docente. 
De acordo com a vivência dos licenciandos temos nas narrativas destes a percepção de como esses saberes advindos das atividades potencialmente significativas colaboram na formação inicial em Química. Assim, Moreira (2011, p.51) aponta que a aprendizagem potencialmente significativa está diretamente relacionada "à postura docente, de uma nova diretriz escolar, do que de novas metodologias”. Essa ideia corrobora com as narrativas de alguns participantes do projeto aqui identificados como bolsista do PIBID/CEUNES QUÍMICA 1, 2, $3,4,5 \ldots . .10$.

Neste momento, apresenta-se a relação dos conceitos envolvidos nos processos formativos docentes com os dados analisados no diagrama V de Gowin que aparecem na Figura 5, na qual reconhecemos que esse instrumento de análise estabelece interface entre a formação da identidade docente com essa referência de ensino demonstrada nos elementos do diagrama.

Assim, torna-se possível compreender a especificidade das questões apresentadas no diagrama conferindo aos bolsistas mais uma possibilidade de se tornar docente em sua trajetória. No cenário da complexidade do ensino, o bolsista tem a oportunidade de utilizar o diagrama estabelecendo relações entre a formação em processo ao longo das atividades desenvolvidas no ambiente escolar. Tal análise aparece nas narrativas ora apresentadas:

Bolsista 1- "A realização das atividades na escola dá um retorno de aprendizagem para os licenciandos, pois assim aprendemos a lidar com o meio escolar. ”

Bolsista 2 - "Conviver com o meio escolar me fazer prender a lidar com situações que possam acontecer na minha vida profissional. ”

Bolsista 7 - "Nem sempre a maneira como preparamos as atividades agrada aos alunos. Isso às vezes deixa a gente um pouco chateado, mas ajuda a refletir de forma crítica o preparo das atividades. ”

Para Tardif (2014, p.123) o ensino é uma atividade incorporada de diversos elementos que determinam o trabalho docente em relação à metodologia utilizada, os instrumentos pedagógicos, os saberes do professor, a dinâmica do seu ofício que em conjunto promovem a construção dos saberes docentes, como aponta a opinião de alguns bolsistas PIBID/CEUNES/QUÍMICA:

Bolsista 10 - "Ao participar da preparação das atividades, o aluno do PIBID adquire maior conhecimento em relação à práticas docentes eficazes que podem ser futuramente utilizados na profissão de professor. ”

Bolsista 4 - "Uma avaliação positiva desse tipo de atividade é que posso ajudar os alunos da escola de Educação Básica e relembrar alguns conceitos e aprender também com eles. Uma coisa que seria "negativa" que preciso aprimorar é a forma de ensinar que as vezes eles não entendem, preciso procurar ser o mais claro possivel, explicar de forma simples. ”

Bolsista 2 - "A atuação nas atividades da escola contribui na melhoria da minha didática, pois o contato com os alunos e junto com o conhecimento da graduação, pude controlar o nervosismo, dialogar com mais transparência, e assim trabalhar o conteúdo com mais segurança e confiança. ”

Na perspectiva da construção de conhecimentos advindos de experiências diversas, Schön (1992) analisa a necessidade de estruturação dos saberes docentes diante de situações que segundo o autor "exigem tempo, prática, experiência e hábito”. Assim alguns bolsistas analisam seu contato com essas ações:

Bolsista 8 - “Nem tudo que vemos na graduação podemos aplicar exatamente igual, tudo tem que ser aperfeiçoado de acordo com a realidade dos alunos da escola. " 
Bolsista 6 - “ A experiência vivenciada no desenvolvimento das atividades, vem da minha formação da graduação, no sentido de buscar aplicar os conhecimentos tanto específicos de química, quanto os adquiridos nas disciplinas didático/pedagógicas. ”

Bolsista 4 - “ No começo sentia vergonha de falar em público e de perguntar quem tinha dúvida e não conseguir responder. Hoje o PIBID me fez mudar, agora consigo explicar um assunto que antes ficava meio receosa de não saber passar para os alunos, além de ter mais contato com os alunos. ”

Bolsista 7 - “As atividades na escola ajudam a ambientar os licenciandos com o seu futuro local de trabalho, além de auxiliá-lo no desenvolvimento de suas metodologias de ensino. ”

Vivenciar a rotina escolar com olhar não mais de aluno, mas sim de futuro professor, as experiências vivenciadas no ambiente escolar, a superação dos desafios pedagógicos e do campo prático de atividades docentes, a movimentação de saberes que colaboram na constituição da identidade docente promove relações entre teoria e prática pedagógica que potencialmente colaboram na formação inicial de professores.

\section{CONSIDERAÇÕES}

As ações pedagógicas dos docentes superam os limites de aprendizagens advindos apenas da teoria, se tornando eixos estruturantes dos saberes práticos necessários à profissão. A formação inicial de professores é uma parte decisiva da constituição da identidade docente e é nesse momento que se torna pertinente o contato entre os licenciandos e o ambiente escolar, atuando efetivamente na produção de novos e outros conhecimentos.

Nas últimas décadas o ensino de Química vem passando por modificações essenciais nas estruturas formativas dos futuros professores. Nesse sentido, o ensino propedêutico que há muito foi o modelo de ensino quase exclusivamente aplicado nas salas de aulas brasileiras, deu lugar a um ensino de química que coloca o sujeito participante do processo formativo como protagonista de sua aprendizagem, superando barreiras com a contextualização no ensino e a interdisciplinaridade, que se fez presente a partir das orientações educacionais sugeridas a um ensino que proporciona ao cidadão o desenvolvimento de competências e habilidades. Segundo Moraes, Ramos e Galiazzi (2006, p. 90), as “crenças, valores, teorias expressas pela linguagem e a capacidade de estar aberto a ouvir e procurar entender os argumentos dos outros e que possibilitam avançar distintamente o conhecimento de cada um dos envolvidos nas situações educativas”, mobilizando assim saberes advindos da prática escolar.

O desenvolvimento desse trabalho favoreceu aos bolsistas participantes do PIBID/CEUNES/QUÍMICA atribuírem novos significados as metodologias de ensino utilizadas, bem como ao processo de ensino e aprendizagem em que foram mobilizados saberes advindos das interações estabelecidas entre o objeto de ensino potencialmente significativo e a construção de saberes nas relações entre licenciandos e alunos da Educação Básica. A utilização dos recursos criados pelos bolsistas do PIBID/CEUNES/QUÍMICA permitiu a estes constituir relações que favorecessem a apropriação de significados junto aos alunos da escola e também aos próprios licenciandos, que puderam articular saberes que subsidiarão sua futura prática profissional.

A superação de métodos de ensinos estáticos, que colocam tanto alunos quanto professores em estado de passividade perante a dinâmica da construção de conhecimentos, é apresentada e analisada no V de Gowin como uma possibilidade de interação dos saberes teóricos aliados aos saberes práticos vislumbrando a potencialidade de ações significativas durante a formação docente.

Atribui-se as ações docentes a possibilidade de promover atitudes educativas que colaborem com o desenvolvimento de saberes formativos profissionais aliados ao cotidiano social do aluno. Para que tal tarefa seja possível torna-se indispensável aos processos de formação de professores ações que promovam aos licenciandos a 
articulação entre teoria e prática potencialmente significativa, a partir das necessidades atuais de aprendizagens. Essas perspectivas de trabalho e formação colaboram na estruturação dos saberes docentes e melhor afirmam referenciais teórico metodológicos na educação, como a do professor reflexivo, a da aprendizagem significativa, o do trabalho interdisciplinar e do professor pesquisador, colaborando especialmente para a formação da identidade docente.

\section{REFERENCIAS}

Ausubel, D.P; Novak, J.D \& Hanesian, H. (1980). Psicologia educacional. Rio de Janeiro, interamericana.

Braathen, P.C. (2012) Aprendizagem mecânica e aprendizagem significativa no processo de ensino-aprendizagem de Química. In: Revista Eixo n. 1, v. 1, 63-69.

Brasil, Ministério da Educação. (1996) Parâmetros Curriculares Nacionais do Ensino Médio: Ciências da Natureza, Matemática e suas Tecnologias. Brasília: Ministério da Educação e Cultura. Acesso em 02 mar, 2015, http://portal.mec.gov.br/seb/arquivos/pdf/ciencian.pdf.

Bogdan, R.; Biklen, S. - Características da investigação qualitativa. In: Investigação qualitativa em educação: uma introdução à teoria e aos métodos. Porto, Porto Editora, 1994. p.47- 51

Espírito Santo (ESTADO). (2008) Secretaria da Educação. Currículo Básico Escola Estadual. Ensino médio: área das Ciências da Natureza e suas tecnologias. Secretaria da Educação. Vitória: SEDU.

Esteban, T.; Zaccur E. (org.). (2002). Professora-pesquisadora-uma práxis em construção. Rio de Janeiro: DP\&A.

Freire, P. (1996). Pedagogia da autonomia. São Paulo: Paz e terra.

GIL, A. C. Métodos e técnicas de pesquisa social. 5. ed. São Paulo: Atlas,2008.

Machado, A. H. (1999). Aula de química: discurso e conhecimento. Ijuí: UNIJUÍ.

Maldaner, O. A.; Zanon L. B.; Bazzan, A. C.; Driemeyer, P. R.; Prado M.P. \& Lauxen, M. T. C. (2007). Currículo contextualizado na área de Ciências da Natureza e suas Tecnologias: a situação de estudo. In: Zanon, L.B.; Maldaner, O.A. (Orgs.). Fundamentos e propostas de ensino de Química para a Educação Básica no Brasil. (pp. 109 -138). (Coleção Educação em Química). Ijuí: Ed. Unijuí.

Moraes, R., Ramos, M. G., Galiazzi, M. C. (2006). A epistemologia do aprender no educar pela pesquisa em Ciências - alguns pressupostos teóricos. In: R. Moraes \& R. Mancuso (Orgs.) Educação em Ciências: produção de currículos e formação de professores. (Coleção Educação em Ciências). Ijuí: Editora Unijuí.

Moreira, M. A. (1999a). Aprendizagem significativa. Brasília: Unb.

Moreira, M. A. (1999b.) Teorias de Aprendizagem. São Paulo: Pedagógica e Universitária.

Moreira, M.A. e Massoni, N.T. (2011). Epistemologia do século XX. São Paulo: Editora Pedagógica Universitária.

Moreira, M.A. (2008). Negociação de significados e aprendizagem significativa. Meaningful Learning and the Negotiation of Meanings. Acesso em 25 de fev. 2015.Disponível em http: //www.ensinosaudeambiente.uff.br / index.php/ ensinosaudeambiente/dez.2008. 
Novak, Joseph D. \& Gowin, D. Bob (1996). Aprender a aprender. Lisboa: Plátano Edições Técnicas. Traduções ao português, de Carla Valadares, do original Learning how to learn.

Nóvoa, A. (2009). Professores: imagens do futuro presente. Lisboa, Ed. Educa.

Roldão, M.C. (2005). Formação de professores, construção do saber profissional e cultura da profissionalização: que triangulação? In: Alonso, Luísa; Roldão, M. Céu (Orgs.). Ser professor de $\mathbf{1}^{\mathbf{0}}$ ciclo - construindo a profissão. (pp. 13-26). Braga: CESC/ Almedina.

Schön, D. (1992). Formar professores como profissionais reflexivos. In: Nóvoa, A. (org.). Os professores e a sua formação. (pp.77-91) Lisboa: Dom Quixote.

Tardif, M. (2014). Saberes docentes e formação profissional. Petrópolis, RJ: Editora Vozes.

Tardif, M.; Lessard, C. (2005) O Trabalho Docente: elementos para uma teoria da docência como profissão de interações humanas. Petrópolis, RJ: Vozes.

Vygotsky, L.S. (1988). A formação social da mente. $2^{\mathrm{a}}$ ed. Brasileira. São Paulo: Martins Fontes. 